\title{
A biographical sketch of an infant
}

\section{Charles Darwin (1877)}

First published in Mind, 2, 285-294.

(reproduced from Christopher Green's Classics)

doi : 10.5214/ans.0972.7531.1017409

M. Taine's very interesting account of the mental development of an infant, translated in the last number of MIND (p. 252), has led me to look over a diary which I kept thirty-seven years ago with respect to one of my own infants. I had excellent opportunities for close observation, and wrote down at once whatever was observed. My chief object was expression, and my notes were used in my book on this subject; but as I attended to some other points, my observations may possibly possess some little interest in comparison with those by M. Taine, and with others which hereafter no doubt will be made. I feel sure, from what I have seen with my own infants, that the period of development of the several faculties will be found to differ considerably in different infants.

During the first seven days various reflex actions, namely sneezing, hickuping, yawning, stretching, and of course sucking and screaming, were well performed by my infant. On the seventh day, I touched the naked sole of his foot with a bit of paper, and he jerked it away, curling at the same time his toes, like a much older child when tickled. The perfection of these reflex movements shows that the extreme imperfection of the voluntary ones is not due to the state of the muscles or of the coordinating centres, but to that of the seat of the will. At this time, though so early, it seemed clear to me that a warm soft hand [p. 286] applied to his face excited a wish to suck. This must be considered as a reflex or an instinctive action, for it is impossible to believe that experience and association with the touch of his mother's breast could so soon have come into play. During the first fortnight he often started on hearing any sudden sound, and blinked his eyes. The same fact was observed with some of my other infants within the first fortnight. Once, when he was 66 days old, I happened to sneeze, and he started violently, frowned, looked frightened, and cried rather badly: for an hour afterwards he was in a state which would be called nervous in an older person, for every slight noise made him start. A few days before this same date, he first started at an object suddenly seen; but for a long time afterwards sounds made him start and wink his eyes much more frequently than did sight; thus when 114 days old, I shook a paste-board box with comfits in it near his face and he started, whilst the same box when empty or any other object shaken as near or much nearer to his face produced no effect. We may infer from these several facts that the winking of the eyes, which manifestly serves to protect them, had not been acquired through experience. Although so sensitive to sound in a general way, he was not able even when 124 days old easily to recognise whence a sound proceeded, so as to direct his eyes to the source.

With respect to vision, - his eyes were fixed on a candle as early as the 9th day, and up to the 45th day nothing else seemed thus to fix them; but on the 49th day his attention was attracted by a bright-coloured tassel, as was shown by his eyes becoming fixed and the movements of his arms ceasing. It was surprising how slowly he acquired the power of following with his eyes an object if swinging at all rapidly; for he could not do this well when seven and a half months old. At the age of 32 days he perceived his mother's bosom when three or four inches from it, as was shown by the protrusion of his lips and his eyes becoming fixed; but I much doubt whether this had any connection with vision; he certainly had not touched the bosom. Whether he was guided through smell or the sensation of warmth or through association with the position in which he was held, I do not at all know.

The movements of his limbs and body were for a long time vague and purposeless, and usually performed in a jerking manner; but there was one exception to this rule, namely, that from a very early period, certainly long before he was 40 days old, he could move his hands to his own mouth. When 77 days old, he took the sucking bottle (with which he was partly fed) in his right hand, whether he was held on the left or right arm of his nurse, and he would not take it in his left hand [p. 287] until a week later although I tried to make him do so; so that the right hand was a week in advance of the left. Yet this infant afterwards proved to be left-handed, the tendency being no doubt inherited - his grandfather, mother, and a brother having been or being left-handed. When between 80 and 90 days old, he drew all sorts of objects into his mouth, and in two or three weeks' time could do this with some skill; but he often first touched his nose with the object and then dragged it down into his mouth. After grasping my finger and drawing it down into his mouth, his own hand prevented him from sucking it; but on the 114th day, after acting in this manner, he slipped his own hand down so that he could get the end of my finger into his mouth. This action was repeated several times, and evidently was not a chance but a rational one. The intentional movements of the hands and arms were thus much in advance of those of the body and legs; though the purposeless movements of the latter were from a very early period usually alternate as in the act of walking. When four months old, he often looked intently at his own hands and other objects close to him, and in doing so the eyes were turned much inwards, so that he often squinted frightfully. In a fortnight after this time (i.e. 132 days old) I observed that if an object was brought as near to his face as his own hands were, he tried to seize it, but often failed; and he did not try to do so in regard to more distant objects. I think there can be little doubt that the convergence of his eyes gave him the clue and excited him to move his arms. Although this infant thus began to use his hands at an early period, he showed no special aptitude in this respect, for when he was 2 years and 4 months old, he held pencils, pens, and other objects far less neatly and efficiently than did his sister who was then only 14 months old, and who showed great inherent aptitude in handling anything.

Anger. - It was difficult to decide at how early an age anger was felt; on his eighth day he frowned and wrinkled the skin round his eyes before a crying fit, but this may have been due to pain or distress, and not to anger. When about ten weeks old, he was given some rather cold milk and he kept a slight 
frown on his forehead all the time that he was sucking, so that he looked like a grown-up person made cross from being compelled to do something which he did not like. When nearly four months old, and perhaps much earlier, there could be no doubt, from the manner in which the blood gushed into his whole face and scalp, that he easily got into a violent passion. A small cause sufficed; thus, when a little over seven months old, he screamed with rage because a lemon slipped away and he could not seize it with his hands. When eleven months old, if [p. 288] a wrong plaything was given to him, he would push it away and beat it; I presume that the beating was an instinctive sign of anger, like the snapping of the jaws by a young crocodile just out of the egg, and not that he imagined he could hurt the plaything. When two years and three months old, he became a great adept at throwing books or sticks, \&c., at anyone who offended him; and so it was with some of my other sons. On the other hand, I could never see a trace of such aptitude in my infant daughters; and this makes me think that a tendency to throw objects is inherited by boys.

Fear. - This feeling is probably one of the earliest which is experienced by infants, as shown by their starting at any sudden sound when only a few weeks old, followed by crying. Before the present one was 4 1/2 months old I had been accustomed to make close to him many strange and loud noises, which were all taken as excellent jokes, but at this period I one day made a loud snoring noise which I had never done before; he instantly looked grave and then burst out crying. Two or three days afterwards, I made through forgetfullness the same noise with the same result. About the same time (viz. on the 137th day) I approached with my back towards him and then stood motionless; he looked very grave and much surprised, and would soon have cried, had I not turned round; then his face instantly relaxed into a smile. It is well known how intensely older children suffer from vague and undefined fears, as from the dark, or in passing an obscure corner in a large hall, \&c. I may give as an instance that I took the child in question, when $21 / 4$ years old, to the Zoological Gardens, and he enjoyed looking at all the animals which were like those that he knew, such as deer, antelopes \&c., and all the birds, even the ostriches, but was much alarmed at the various larger animals in cages. He often said afterwards that he wished to go again, but not to see "beasts in houses"; and we could in no manner account for this fear. May we not suspect that the vague but very real fears of children, which are quite independent of experience, are the inherited effects of real dangers and abject superstitions during ancient savage times? It is quite conformable with what we know of the transmission of formerly well-developed characters, that they should appear at an early period of life, and afterwards disappear.

Pleasurable Sensations. - It may be presumed that infants feel pleasure whilst sucking and the expression of their swimming eyes seems to show that this is the case. This infant smiled when 45 days, a second infant when 46 days old; and these were true smiles, indicative of pleasure, for their eyes brightened and eyelids slightly closed. The smiles arose chiefly when looking at their mother, and were therefore probably of mental origin; [p. 289] but this infant often smiled then, and for some time afterwards, from some inward pleasurable feeling, for nothing was happening which could have in any way excited or amused him. When 110 days old he was exceedingly amused by a pinafore being thrown over his face and then suddenly withdrawn; and so he was when I suddenly uncovered my own face and approached his. He then uttered a little noise which was an incipient laugh. Here surprise was the chief cause of the amusement, as is the case to a large extent with the wit of grown-up persons. I believe that for three or four weeks before the time when he was amused by a face being suddenly uncovered, he received a little pinch on his nose and cheeks as a good joke. I was at first surprised at humour being appreciated by an infant only a little above three months old, but we should remember how very early puppies and kittens begin to play. When four months old, he showed in an unmistakable manner that he liked to hear the pianoforte played; so that here apparently was the earliest sign of an æsthetic feeling, unless the attraction of bright colours, which was exhibited much earlier, may be so considered.

Affection. - This probably arose very early in life, if we may judge by his smiling at those who had charge of him when under two months old; though I had no distinct evidence of his distinguishing and recognising anyone, until he was nearly four months old. When nearly five months old, he plainly showed his wish to go to his nurse. But he did not spontaneously exhibit affection by overt acts until a little above a year old, namely, by kissing several times his nurse who had been absent for a short time. With respect to the allied feeling of sympathy, this was clearly shown at 6 months and 11 days by his melancholy face, with the corners of his mouth well depressed, when his nurse pretended to cry. Jealousy was plainly exhibited when I fondled a large doll, and when I weighed his infant sister, he being then $151 / 2$ months old. Seeing how strong a feeling jealousy is in dogs, it would probably be exhibited by infants at an earlier age than that just specified, if they were tried in a fitting manner.

Association of Ideas, Reason, \&c. - The first action which exhibited, as far as I observed, a kind of practical reasoning, has already been noticed, namely, the slipping his hand down my finger so as to get the end of it into his mouth; and this happened on the 114th day. When four and a half months old, he repeatedly smiled at my image and his own in a mirror, and no doubt mistook them for real objects; but he showed sense in being evidently surprised at my voice coming from behind him. Like all infants he much enjoyed thus looking at himself, and in less than two months perfectly understood that it was [p. 290] an image; for if I made quite silently any odd grimace, he would suddenly turn round to look at me. He was, however, puzzled at the age of seven months, when being out of doors he saw me on the inside of a large plate-glass window, and seemed in doubt whether or not it was an image. Another of my infants, a little girl, when exactly a year old, was not nearly so acute, and seemed quite perplexed at the image of a person in a mirror approaching her from behind. The higher apes which I tried with a small looking-glass behaved differently; they placed their hands behind the glass, and in doing so showed their sense, but far from taking pleasure in looking at themselves they got angry and would look no more.

When five months old, associated ideas arising independently of any instruction became fixed in his mind; thus as soon as his hat and cloak were put on, he was very cross if he was not immediately taken out of doors. When exactly seven months old, he made the great step of associating his nurse with her name, so that if I called it out he would look round for her. Another infant used to amuse himself by shaking his head laterally: we praised and imitated him, saying "Shake your head"; and when 
he was seven months old, he would sometimes do so on being told without any other guide. During the next four months the former infant associated many things and actions with words; thus when asked for a kiss he would protrude his lips and keep still, - would shake his head and say in a scolding voice "Ah" to the coal-box or a little spilt water, \&c., which he had been taught to consider as dirty. I may add that when a few days under nine months old he associated his own name with his image in the looking-glass, and when called by name would turn towards the glass even when at some distance from it. When a few days over nine months, he learnt spontaneously that a hand or other object causing a shadow to fall on the wall in front of him was to be looked for behind. Whilst under a year old, it was sufficient to repeat two or three times at intervals any short sentence to fix firmly in his mind some associated idea. In the infant described by M. Taine (pp. 254-256) the age at which ideas readily became associated seems to have been considerably later, unless indeed the earlier cases were overlooked. The facility with which associated ideas due to instruction and others spontaneously arising were acquired, seemed to me by far the most strongly marked of all the distinctions between the mind of an infant and that of the cleverest full-grown dog that I have ever known. What a contrast does the mind of an infant present to that of the pike, described by Professor Möbius,[1] who during three whole months dashed and [p. 291] stunned himself against a glass partition which separated him from some minnows; and when, after at last learning that he could not attack them with impunity, he was placed in the aquarium with these same minnows, then in a persistent and senseless manner he would not attack them!

Curiosity, as M. Taine remarks, is displayed at an early age by infants, and is highly important in the development of their minds; but I made no special observation on this head. Imitation likewise comes into play. When our infant was only four months old I thought that he tried to imitate sounds; but I may have deceived myself, for I was not thoroughly convinced that he did so until he was ten months old. At the age of $111 / 2$ months he could readily imitate all sorts of actions, such as shaking his head and saying "Ah" to any dirty object, or by carefully and slowly putting his forefinger in the middle of the palm of his other hand, to the childish rhyme of "Pat it and pat it and mark it with T". It was amusing to behold his pleased expression after successfully performing any such accomplishment.

I do not know whether it is worth mentioning, as showing something about the strength of memory in a young child, that this one when 3 years and 23 days old on being shown an engraving of his grandfather, whom he had not seen for exactly six months, instantly recognised him and mentioned a whole string of events which had occurred whilst visiting him, and which certainly had never been mentioned in the interval.

Moral Sense. - The first sign of moral sense was noticed at the age of nearly 13 months: I said "Doddy (his nickname) won't give poor papa a kiss, - naughty Doddy". These words, without doubt, made him feel slightly uncomfortable; and at last when I had returned to my chair, he protruded his lips as a sign that he was ready to kiss me; and he then shook his hand in an angry manner until I came and received his kiss. Nearly the same little scene recurred in a few days, and the recon- ciliation seemed to give him so much satisfaction, that several times afterwards he pretended to be angry and slapped me, and then insisted on giving me a kiss. So that here we have a touch of the dramatic art, which is so strongly pronounced in most young children. About this time it became easy to work on his feelings and make him do whatever was wanted. When 2 years and 3 months old, he gave his last bit of gingerbread to his little sister, and then cried out with high self-approbation "Oh kind Doddy, kind Doddy". Two months later, he became extremely sensitive to ridicule, and was so suspicious that he often thought people who were laughing and talking together were laughing at him. A little later (2 years and 71/2 months old) I met him [p. 292] coming out of the dining room with his eyes unnaturally bright, and an odd unnatural or affected manner, so that I went into the room to see who was there, and found that he had been taking pounded sugar, which he had been told not to do. As he had never been in any way punished, his odd manner certainly was not due to fear, and I suppose it was pleasurable excitement struggling with conscience. A fortnight afterwards, I met him coming out of the same room, and he was eyeing his pinafore which he had carefully rolled up; and again his manner was so odd that I determined to see what was within his pinafore, notwithstanding that he said there was nothing and repeatedly commanded me to "go away," and I found it stained with pickle-juice; so that here was carefully planned deceit. As this child was educated solely by working on his good feelings, he soon became as truthful, open, and tender, as anyone could desire.

Unconsciousness, Shyness. - No one can have attended to very young children without being struck at the unabashed manner in which they fixedly stare without blinking their eyes at a new face; an old person can look in this manner only at an animal or inanimate object. This, I believe, is the result of young children not thinking in the least about themselves, and therefore not being in the least shy, though they are sometimes afraid of strangers. I saw the first symptom of shyness in my child when nearly two years and three months old: this was shown towards myself, after an absence of ten days from home, chiefly by his eyes being kept slightly averted from mine; but he soon came and sat on my knee and kissed me, and all trace of shyness disappeared.

Means of Communication. - The noise of crying or rather of squalling, as no tears are shed for a long time, is of course uttered in an instinctive manner, but serves to show that there is suffering. After a time the sound differs according to the cause, such as hunger or pain. This was noticed when this infant was eleven weeks old, and I believe at an earlier age in another infant. Moreover, he appeared soon to learn to begin crying voluntarily, or to wrinkle his face in the manner proper to the occasion, so as to show that he wanted something. When 46 days old, he first made little noises without any meaning to please himself, and these soon became varied. An incipient laugh was observed on the 113th day, but much earlier in another infant. At this date I thought, as already remarked, that he began to try to imitate sounds, as he certainly did at a considerably later period. When five and a half months old, he uttered an articulate sound "da" but without any meaning attached to it. When a little over a year old, he used gestures [p. 293] to explain his wishes; to give a simple instance, he picked up a bit of paper and giving it to me pointed to the fire, as he had often seen and liked to see paper burnt. At exactly the age of a year, 
he made the great step of inventing a word for food, namely mum, but what led him to it I did not discover. And now instead of beginning to cry when he was hungry, he used this word in a demonstrative manner or as a verb, implying "Give me food". This word therefore corresponds with ham as used by M. Taine's infant at the later age of 14 months. But he also used mum as a substantive of wide signification; thus he called sugar shu-mum, and a little later after he had learned the word "black," he called liquorice black-shu-mum, - black-sugar-food.

I was particularly struck with the fact that when asking for food by the word mum he gave to it (I will copy the words written down at the time) "a most strongly marked interrogatory sound at the end". He also gave to "Ah," which he chiefly used at first when recognising any person or his own image in a mirror, an exclamatory sound, such as we employ when surprised. I remark in my notes that the use of these intonations seemed to have arisen instinctively, and I regret that more observations were not made on this subject. I record, however, in my notes that at a rather later period, when between 18 and 21 months old, he modulated his voice in refusing peremptorily to do anything by a defiant whine, so as to express "That I won't"; and again his humph of assent expressed "Yes, to be sure". $M$. Taine also insists strongly on the highly expressive tones of the sounds made by his infant before she had learnt to speak. The interrogatory sound which my child gave to the word mum when asking for food is especially curious; for if anyone will use a single word or a short sentence in this manner, he will find that the musical pitch of his voice rises considerably at the close. I did not then see that this fact bears on the view which I have elsewhere maintained that before man used articulate language, he uttered notes in a true musical scale as does the anthropoid ape Hylobates.

Finally, the wants of an infant are at first made intelligible by instinctive cries, which after a time are modified in part unconsciously, and in part, as I believe, voluntarily as a means of communication, - by the unconscious expression of the features, - by gestures and in a marked manner by different intonations, - lastly by words of a general nature invented by himself, then of a more precise nature imitated from those which he hears; and these latter are acquired at a wonderfully quick rate. An infant understands to a certain extent, and as [p. 294] I believe at a very early period, the meaning or feelings of those who tend him, by the expression of their features. There can hardly be a doubt about this with respect to smiling; and it seemed to me that the infant whose biography I have here given understood a compassionate expression at a little over five months old. When 6 months and 11 days old he certainly showed sympathy with his nurse on her pretending to cry. When pleased after performing some new accomplishment, being then almost a year old, he evidently studied the expression of those around him. It was probably due to differences of expression and not merely of the form of the features that certain faces clearly pleased him much more than others, even at so early an age as a little over six months. Before he was a year old, he understood intonations and gestures, as well as several words and short sentences. He understood one word, namely, his nurse's name, exactly five months before he invented his first word mum; and this is what might have been expected, as we know that the lower animals easily learn to understand spoken words. 